INTENSIF, Vol.3 No.1 February 2019

ISSN: 2580-409X (Print) / 2549-6824 (Online)

Website: http://ojs.unpkediri.ac.id/index.php/intensif

\title{
Sistem Pendukung Keputusan Pemilihan Rumah di Kawasan Cepu Menggunakan Analytical Hierarchy Process
}

\section{Decision Support System for the Election of Houses in Cepu Area Using Analytical} Hierarchy Process

\author{
${ }^{1}$ Adhika Pramita Widyassari, ${ }^{2}$ Teguh Yuwono \\ ${ }^{1,2}$ Sekolah Tinggi Teknologi Ronggolawe Cepu \\ ${ }_{1,2}$ Blora, Indonesia \\ E-mail: '1adhika@sttrcepu.ac.id, ${ }^{2}$ ridalutfiah@gmail.com
}

\begin{abstract}
Abstrak-Strategi membeli rumah, konsumen seringkali mengalami masalah dalam menentukan rumah yang akan dibeli, karena setiap rumah tersebut mempunyai karakteristik yang berbeda. Karakteristik-karakteristik tersebut akan digunakan sebagai acuan pertimbangan dalam menentukan rumah mana yang akan dibeli. Dalam penelitian ini digunakan metode AHP (Analytical Hierarchy Process) untuk pembobotan kriteria dan uji tingkat konsistensi terhadap matriks perbandingan berpasangan. Jika matriks telah konsisten maka dapat dilanjutkan melakukan perangkingan untuk menentukan alternatif terpilih dengan menggunakan input bobot kriteria yang diperoleh dari metode AHP. Untuk mengatasi permasalahan di atas, maka perlu dibangun suatu sistem pendukung keputusan dengan menerapkan suatu perangkingan yang dapat mempermudah menentukan Pemilihan Rumah dengan menggunakan metode AHP (Analytical Hierarchy Process). Dari 9 sample rumah di kawasan Cepu, yang mendapatkan nilai tertinggi adalah Perumahan Grand Zam Zam Cepu Tipe 38/78 dengan total nilai 2,84564719.
\end{abstract}

Kata Kunci-Pemilihan Rumah, Sistem Pendukung Keputusan, AHP (Analitycal Hierarchy Process)

Abstract - Strategies to buy a house, consumers often experience problems in determining the house to be purchased, because each house has different characteristics. These characteristics will be used as reference considerations in determining which house to buy. In this study, the AHP (Analytical Hierarchy Process) method was used to weight the criteria and test the level of consistency with the pairwise comparison matrix. If the matrix has been consistent, then it can be continued to rank to determine the chosen alternative by using input weighting criteria obtained from the AHP method. To overcome the above problems, it is necessary to build a decision support system by implementing a ranking that can make it easier to determine House Selection using the AHP (Analytical Hierarchy Process) method. Of the 9 sample houses in the Cepu area, the highest was the Housing of Zam Zam Cepu Type 38/78 with a total value of 2,84564719.

Keywords-House Selection, Decision Support System, AHP (Analytical Hierarchy Process) 
INTENSIF, Vol.3 No.1 February 2019

ISSN: 2580-409X (Print) / 2549-6824 (Online)

Website: http://ojs.unpkediri.ac.id/index.php/intensif

\section{PENDAHULUAN}

Seiring berjalannya waktu, pertumbuhan penduduk di Indonesia setiap tahunnya selalu bertambah sehingga jumlah permintaan kebutuhan tempat tinggal juga meningkat. Ini terbukti dengan semakin banyak dibangun komplek perumahan baru untuk memenuhi kebutuhan tempat tinggal masyarakat, termasuk di Cepu. Cepu dikenal juga sebagai salah satu kawasan minyak di jawa tengah, dengan luas wilayah daerah Cepu 48,97 km2 jumlah penduduk 77.880 jiwa.

Perkembangan dibidang property ini tidak hanya dipengaruhi oleh membaiknya perekonomian tetapi juga minat para konsumen mengikuti perkembangan ini. Peningkatan jumlah konsumen dari tahun ke tahun semakin bertambah. Dengan adanya perumahan berdasarkan kebutuhan banyak pengembang property perumahan berlomba untuk mendapatkan kosumen dengan menawarkan lokasi, fasilitas umum, sistem pembayaran, desain rumah dan kualitas rumah, lingkungan, dan harga yang beragam[1]. Hal inilah yang menyebabkan konsumen harus pandai-pandai memilih perumahan mana yang akan mereka ambil yang sesuai dengan kriteria-kriteria yang diinginkan.

Konsumen sering kali membutuhkan analisa yang cukup mendalam agar pilihan rumah yang akan dibeli tersebut dapat memberikan keuntungan finansial maupun non finansial. Keuntungan finansial berkaitan dengan biaya dan pendapatan, sedangkan keuntungan non finansial berkaitan dengan keuntungan seperti lokasi yang strategis sehingga dapat menarik peminat, lingkungan yang sehat, hingga lingkungan sekitar rumah yang memiliki karakter yang menyenangkan.

Dalam membeli rumah yang akan dibeli, konsumen seringkali mengalami masalah dalam menentukan rumah yang akan dibeli, karena setiap rumah tersebut mempunyai karakteristik yang berbeda. Karakteristik-karakteristik tersebut akan digunakan sebagai acuan pertimbangan dalam menentukan rumah mana yang akan dibeli.

Penelitian ini digunakan langkah teknik sistem pendukung keputusan. Beberapa metode pendukung keputusan seperti diantaranya Simple Additive Weighting (SAW), Weighted Product (WP), ELECTRE, Technique for Order Preference by Similarity to Ideal Solution (TOPSIS), Analytic Hierarchy Process (AHP)[2][3][4][5] . Pada penelitian ini menggunakan metode AHP (Analytical Hierarchy Process) untuk pembobotan kriteria dan uji tingkat konsistensi terhadap matriks perbandingan berpasangan. Jika matriks telah konsisten maka dapat dilanjutkan melakukan perankingan untuk menentukan alternatif terpilih dengan menggunakan input bobot kriteria yang diperoleh dari metode AHP. Metode AHP merupakan salah satu model pengambilan keputusan yang dapat membantu kerangka berfikir manusia[6] .

Metode AHP membantu memecahkan persoalan yang kompleks dengan menstruktur suatu hirarki, kriteria, pihak yang berkepentingan, hasil dan dengan menarik berbagai pertimbangan 
INTENSIF, Vol.3 No.1 February 2019

ISSN: 2580-409X (Print) / 2549-6824 (Online)

Website: http://ojs.unpkediri.ac.id/index.php/intensif

guna mengembangkan bobot atau prioritas. Metode ini menggabungkan antara kekuatan perasaan dan logika yang bersangkutan pada berbagai persoalan, lalu mensintesis berbagai pertimbangan yang beragam menjadi hasil yang cocok dengan perkiraan kita secara intuitif sebagaimana yang dipresentasikan pada pertimbangan yang telah dibuat[7].

Penelitian tentang perumahan menggunakan AHP telah diteliti sebelumnya yaitu berjudul Sistem Penunjang Keputusan Pemilihan Perumahan Dengan Menggunakan Metode AHP. Dimana tujuan dari penelitian ini adalah menganalisis kriteria- kriteria apa saja yang di perlukan dalam pemilihan perumahan. Analisis tersebut akan di skoring melalui kuesioner dan diolah menggunakan metode AHP dengan bantuan software Expert Choice[8]. Kemudian penelitian yang berjudul Pengambilan Keputusan Pemilihan Perumahan Menengah dan Sederhana di Kabupaten Sumenep dengan Analytical Hierarchy Process. Hasil analisis yang mendapat kriteria tertinggi adalah lokasi dengan nilai bobot $25,9 \%$, karena selain dapat memberikan rasa aman dan nyaman juga mempunyai nilai investasi yang tinggi dalam jangka waktu yang lama. Dan perumahan yang direkomendasikan adalah perumahan Satelit Indah dengan nilai bobot $17,54 \%[9]$.

Untuk mengatasi permasalahan di atas, maka perlu dibangun suatu sistem pendukung keputusan dengan menerapkan suatu perangkingan yang dapat mempermudah menentukan Pemilihan Rumah dengan menggunakan metode AHP (Analytical Hierarchy Process). Diharapka dengan adanya sistem pendukung keputusan pemilihan rumah menggunakan metode AHP dapat membantu konsumen untuk memilih rumah yang diinginkan dengan hal yang membedakan dengan penelitian yang sudah pernah dilakukan adalah kriteria yang dipakai untuk pemilihan rumah yaitu harga, lokasi, fasilitas, luas rumah, dan desain.

\section{METODE PENELITIAN}

Metodologi penelitian adalah cara ilmiah yang digunakan dalam memperoleh berbagai data untuk diproses menjadi informasi yang lebih akurat sesuai permasalahan yang akan diteliti. Metodologi penelitian digunakan sebagai pedoman dalam pelaksanaan penelitian agar hasil yang dicapai tidak menyimpang dari tujuan yang telah dilakukan sebelumnya[10]. Metodologi penelitian yang digunakan dalam penyusunan penelitian ini akan melalui beberapa tahapan.

Berikut ini adalah metodologi yang digunakan dalam penelitian yang berjudul "Sistem Pendukung Keputusan Pemilihan Rumah di Kawasan Cepu Menggunakan Analytical Hierarchy Process": 
INTENSIF, Vol.3 No.1 February 2019

ISSN: 2580-409X (Print) / 2549-6824 (Online)

Website: http://ojs.unpkediri.ac.id/index.php/intensif

A. Pengumpulan Data

Pada tahap ini dilakukan dengan pengumpulan data-data yang ada di perusahaan tersebut.

Semua tahap pada proses pengumpulan data-data tersebut diperoleh dari hasil wawancara, observasi dan studi pustaka, dimana dalam penelitian ini data itu meliputi:

1. Data perumahan

Data ini diambil dari hasil observasi di beberapa pengembang/developer perumahan di kawasan Cepu

2. Data pembobotan masing-masing kriteria pemilihan rumah

Data ini diperoleh dari hasil lembar pengisian kepada beberapa pihak yang akan membeli atau berinvestasi rumah di perumahan kawasan Cepu

B. Langkah-langkah Penelitian

1. Pengumpulan data

Data yang dimaksud adalah data rumah, kriteria, rating yang diambil dengan cara observasi dan wawancara.

2. Perancangan Struktur Hirarki.

Setelah data yang dibutuhkan terkumpul, maka dilakukan perancangan struktur hirarki pemilihan rumah yaitu berisikan kriteria dan alternatif pemilihan rumah. Hirarki didefinisikan sebagai suatu representasi dari sebuah permasalahan yang kompleks dalam suatu struktur multi level dimana level pertama adalah tujuan / sasaran, yang diikuti faktor, kriteria, sub kriteria, dan seterusnya ke bawah hingga level terakhir alternatif[11] seperti dijelaskan pada gambar 1.

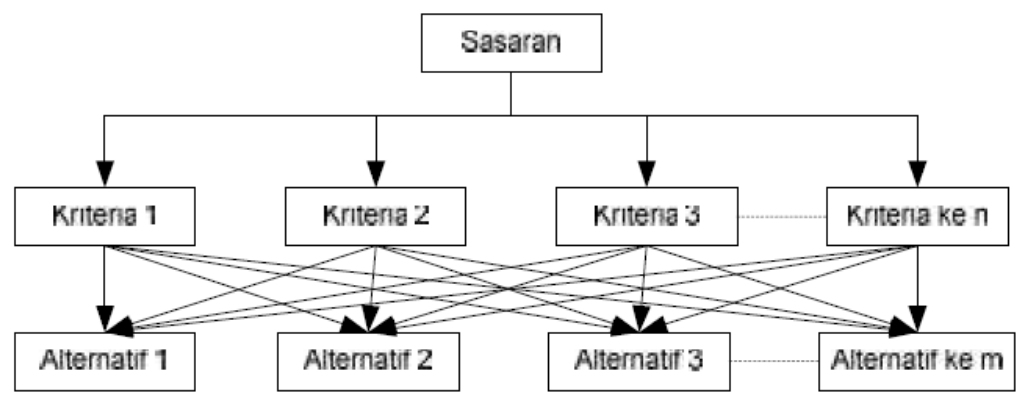

Gambar 1. STRUKTUR HIRARKI

\section{Pengisian Skala Nilai}

Pengisian skala nilai berisi tentang skala banding penilaian antara kriteria pemilihan rumah yang telah diisi oleh beberapa pihak yang akan membeli atau berinvestasi rumah di perumahan kawasan Cepu dengan metode AHP. Skala kepentinga pada metode AHP dijelaskan pada tabel 1. 
INTENSIF, Vol.3 No.1 February 2019

ISSN: 2580-409X (Print) / 2549-6824 (Online)

Website: http://ojs.unpkediri.ac.id/index.php/intensif

Tabel 1. SKALA KEPENTINGAN

\begin{tabular}{lc}
\hline \hline Nilai & Keterangan \\
\hline 1 & Kriteria/Alternatif A sama penting dengan kriteria/alternatif B \\
\hline 3 & A sedikit lebih penting dari B \\
\hline 5 & A jelas lebih penting dari B \\
\hline 7 & A sangat jelas lebih penting dari B \\
\hline 9 & Mutlak lebih penting dari B \\
\hline $2,4,6,8$ & Apabila ragu-ragu antara dua nilai yang berdekatan \\
\hline Kebalikan & Jika alternatif 1 dibandingkan dengan alternatif 2 nilainya 3, maka \\
& alternatif 2 dibandingkan dengan alternatif 1 nilainya 1/3 \\
\hline
\end{tabular}

4. Menentukan Bobot Kriteria Pemilihan Rumah.

Dilakukan untuk menghasilkan bobot dan prioritas masing-masing kriteria pemilihan rumah. Pengolahan dilakukan dengan menggunakan metode AHP yaitu dengan perbandingan matriks berpasangan.

5. Menguji konsistensi

Pengujian ini dilakukan dengan mencari nilai rasio inkonsistensi untuk pemilih rumah. Pengujian ini dilakukan terhadap kriteria pemilihan rumah yang telah ditentukan. Jika nilai rasio konsistensi kurang atau sama dengan 0.1 berarti penilaian dapat dipertanggung jawabkan[12]. Rumus menghitung indeks konsistensi dan ratio konsistensi terdapat pada persamaan 1 dan 2

$$
\begin{gathered}
\text { Consistensi Index }(\mathrm{CI})=C I=\frac{\lambda m a k s-n}{n-1}, \\
\text { Consistensi Ratio }(\mathrm{CR})=\quad C R=\frac{C I}{R I},
\end{gathered}
$$

6. Perhitungan Pemilihan Rumah

Setelah bobot dari masing-masing kriteria diperoleh dan prioritas keseluruhan telah ditentukan, maka masing-masing bobot tersebut dikalikan dengan nilai yang diberikan oleh penilai (dalam hal ini adalah admin berpengalaman yang bertugas di beberapa kantor pengembang perumahan di kawasan Cepu) yang akhirnya jumlah dari seluruh skor tersebut itulah yang menjadi nilai dari rumah yang dinilai untuk kemudian dipilih.

7. Melakukan implementasi ke aplikasi

Membuat aplikasi berbasis web dengan algoritma yang sudah dirancang dan dibuktikan seperti tahap-tahap sebelumnya. Menguji Aplikasi sistem menggunakan pengujian fungsionality yang dilakukan oleh 20 orang. 
INTENSIF, Vol.3 No.1 February 2019

ISSN: 2580-409X (Print) / 2549-6824 (Online)

Website: http://ojs.unpkediri.ac.id/index.php/intensif

\section{HASIL DAN PEMBAHASAN}

\section{A. Analisis Sistem}

Data-data yang dibutuhkan untuk sistem pendukung keputusan pemilihan rumah adalah data rumah, data nilai rumah, data kriteria serta rating dan nilainya. Berikut ini adalah langkah proses AHP:

1. Identifikasi tujuan, kriteria, rating dan nilai rating dalam suatu hirarki

Tujuan : pemilihan rumah

Kriteria : terdiri dari 5 buah kriteria yang berpengaruh dalam pemilihan rumah. Berikut ini adalah kriteria-kriteria yang ditentukan pihak pengembang/developer:

a. Harga. Konsumen lebih memilih harga rumah yang sesuai dengan dana yang mereka punyai.

b. Lokasi. Lokasi perumahan yang strategis lebih dilirik oleh konsumen, misalnya, dekatnya dengan jalan raya, pasar, rumah sakit, tempat kantor, sekolahan, dan banyak lain.

c. Fasilitas Umum. Fasilitas umum disini adalah fasilitas umum yang disediakan pihak developer di lokasi perumahan. Misalnya jalan, masjid, dan area permainan.

d. Luas Tanah. Luas tanah disini menceritakan luas tanah keseluruhan.

e. Desain. Desain ini menceritakan model rumah yang dipilih oleh konsumen.

Sedangkan untuk rating dan nilai rating dari kriteria dapat dilihat pada tabel 2-6:

Tabel 2. RATING DAN NILAI RATING UNTUK KRITERIA HARGA

\begin{tabular}{ccc}
\hline \hline Rating & Range & Nilai Rating \\
\hline Murah & $\mathrm{x}<200$ juta & 3 \\
Sedang & 200 juta $\leq \mathrm{x} \leq 400$ juta & 2 \\
Mahal & $x>400$ juta & 1 \\
\hline
\end{tabular}

Tabel 3. RATING DAN NILAI RATING UNTUK KRITERIA LOKASI

\begin{tabular}{ccc}
\hline \hline Rating & Range & Nilai Rating \\
\hline Strategis & $\mathrm{x}<2 \mathrm{~km}$ dari keramaian & 3 \\
Cukup Strategis & $2 \mathrm{~km}$ dari keramaian $\leq \mathrm{x} \leq 5 \mathrm{~km}$ dari keramaian & 2 \\
Kurang Strategis & $\mathrm{x}>5 \mathrm{~km}$ dari keramaian & 1 \\
\hline
\end{tabular}

Tabel 4. RATING DAN NILAI RATING UNTUK KRITERIA FASILITAS

\begin{tabular}{cc}
\hline \hline Rating & Nilai Rating \\
\hline Lengkap & 3 \\
Cukup Kurang lengkap & 2 \\
Kurang Lengkap & 1 \\
\hline
\end{tabular}


INTENSIF, Vol.3 No.1 February 2019

ISSN: 2580-409X (Print) / 2549-6824 (Online)

Website: http://ojs.unpkediri.ac.id/index.php/intensif

Tabel 5. RATING DAN NILAI RATING UNTUK KRITERIA LUAS TANAH

\begin{tabular}{ccc}
\hline \hline Rating & Range & Nilai Rating \\
\hline Sangat Luas & $\mathrm{x}>100 \mathrm{~m}^{2}$ & 3 \\
Cukup Luas & $50 \mathrm{~m}^{2} \leq \mathrm{x} \leq 100 \mathrm{~m}^{2}$ & 2 \\
Sempit & $\mathrm{x}<50 \mathrm{~m}^{2}$ & 1 \\
\hline
\end{tabular}

Tabel 6. RATING DAN NILAI RATING UNTUK KRITERIA DESAIN

\begin{tabular}{cc}
\hline \hline Rating & Nilai Rating \\
\hline Mewah & 3 \\
Minimalis & 2 \\
RSS & 1 \\
\hline
\end{tabular}

2. Membuat struktur hirarki yang terdiri dari struktur tujuan, kriteria, dan alternatif. Pada gambae 2 merupakan struktur hirarki pada sistem pendukung keputusan pemilihan rumah

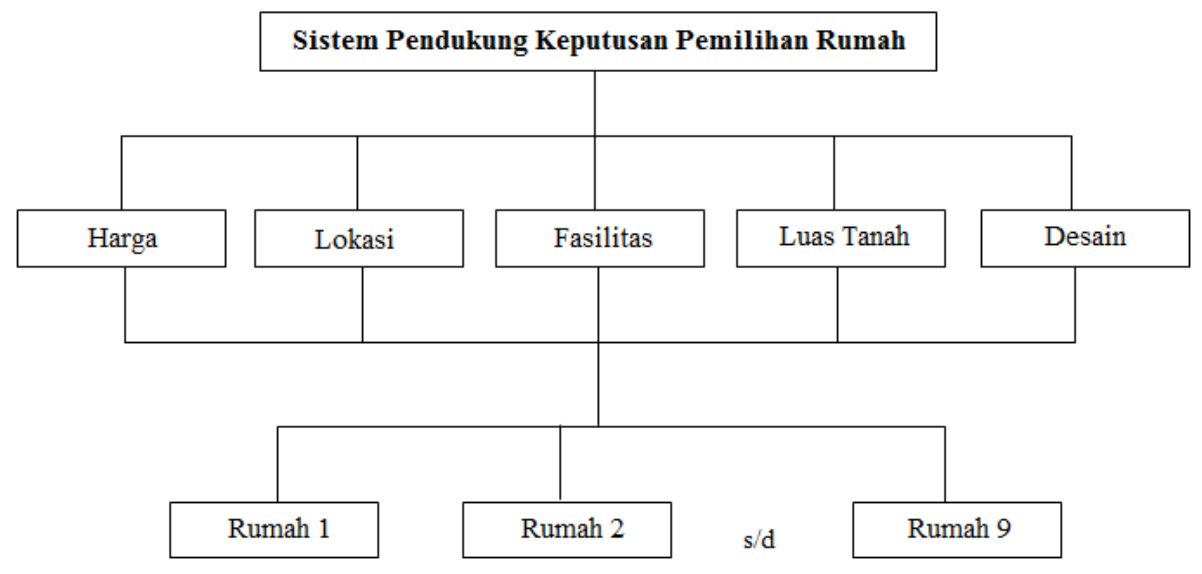

\section{Gambar 2. HIRARKI SISTEM PENDUKUNG KEPUTUSAN PEMILIHAN RUMAH}

3. Melakukan pairwise comparison untuk semua kriteria. Tabel 7-9 merupakan matriks perbandingan berpasangan dari setiap kriteria yang nilainya ditentukan oleh managemen.

Tabel 7. MATRIKS PERBANDINGAN BERPASANGAN

\begin{tabular}{lrrrrr}
\hline & Harga & Lokasi & Fasilitas & Luas & Desain \\
\hline Harga & 1 & 1 & 2 & 3 & 5 \\
\hline Lokasi & 1 & 1 & 0.5 & 3 & 3 \\
\hline Fasilitas & 0.5 & 2 & 1 & 3 & 5 \\
\hline Luas & 0.333 & 0.333 & 0.333 & 1 & 2 \\
\hline Desain & 0.2 & 0.333 & 0.2 & 0.5 & 1 \\
\hline Jml & 3.033 & 4.666 & 4.033 & 10.5 & 16 \\
\hline
\end{tabular}


INTENSIF, Vol.3 No.1 February 2019

ISSN: 2580-409X (Print) / 2549-6824 (Online)

Website: http://ojs.unpkediri.ac.id/index.php/intensif

Tabel 8. PERHITUNGAN PRIORITAS SETIAP KRITERIA

\begin{tabular}{lrrccrrr}
\hline \hline & Harga & lokasi & Fasilitas & Luas & Desain & Jumlah & Prioritas \\
\hline Harga & 0.33 & 0.214 & 0.496 & 0.286 & 0.313 & 1.638 & 0.328 \\
\hline Lokasi & 0.33 & 0.214 & 0.124 & 0.286 & 0.188 & 1.141 & 0.228 \\
\hline Fasilitas & 0.165 & 0.429 & 0.248 & 0.286 & 0.313 & 1.44 & 0.288 \\
\hline Luas & 0.11 & 0.071 & 0.083 & 0.095 & 0.125 & 0.484 & 0.097 \\
\hline Desain & 0.066 & 0.071 & 0.05 & 0.048 & 0.063 & 0.297 & 0.059 \\
\hline Jumlah & 1 & 1 & 1 & 1 & 1 & 5 & 1 \\
\hline
\end{tabular}

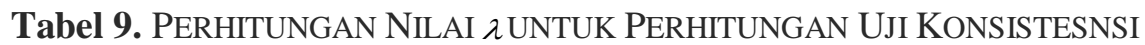

\begin{tabular}{lrrrrrrrr}
\hline \hline & Harga & Lokasi & Fasilitas & Luas & Desain & Jml & Bobot & $\lambda$ \\
\hline Harga & 0.328 & 0.228 & 0.576 & 0.29 & 0.297 & 1.719 & 0.328 & 5.247 \\
\hline Lokasi & 0.328 & 0.228 & 0.144 & 0.29 & 0.178 & 1.168 & 0.228 & 5.119 \\
\hline Fasilitas & 0.164 & 0.456 & 0.288 & 0.29 & 0.297 & 1.496 & 0.288 & 5.194 \\
\hline Luas & 0.109 & 0.076 & 0.096 & 0.097 & 0.119 & 0.497 & 0.097 & 5.13 \\
\hline Desain & 0.066 & 0.076 & 0.058 & 0.048 & 0.059 & 0.307 & 0.059 & 5.167 \\
\hline Jumlah & 0.994 & 1.065 & 1.161 & 1.016 & 0.95 & 5.187 & 1 & 25.86 \\
\hline
\end{tabular}

Menghitung prioritas rating dengan cara membandingkan nilai rating dengan total nilai rating. Untuk menghitung prioritas ideal, normalisasi dengan cara membagi setiap prioritas dengan nilai tertinggi dari setiap prioritas.

$$
\begin{aligned}
& \lambda \text { nax }=\frac{\text { total }}{\text { jumlah kriteria }}=\frac{25.86}{5}=5.1716 \\
& \begin{aligned}
\mathrm{CI} & =\frac{\lambda \text { maks }-\mathrm{n}}{\mathrm{n}-1}=\frac{5,1716-5}{5-1}=\frac{0,1716}{4}=0,0429 \\
C R & =\frac{C I}{R I} \\
& =\frac{0,0429}{1,12}=0,038
\end{aligned}
\end{aligned}
$$

Karena nilai consistensi ratio $<0,10$ : jadi kriteria penilaian konsisten dan dapat diterima (acceptable).

Tabel 10. Perhitungan Bobot Setiap Rumah

\begin{tabular}{ccccccc}
\hline \hline Rumah & \multicolumn{5}{c}{ Kriteria } & \multirow{2}{*}{ Bobot } \\
\cline { 2 - 6 } & Harga & Lokasi & Fasilitas & $\begin{array}{c}\text { Luas } \\
\text { Tanah }\end{array}$ & Desain & \\
\hline Rumah-1 & 0.999909 & 0.449091 & 0.854213 & 0.191149 & 0.117557 & 2.62110174 \\
Rumah-2 & 0.333303 & 0.449091 & 0.864213 & 0.191149 & 0.117557 & 1.96604551 \\
Rumah-9 & 0.666061 & 0.673636 & 0.576142 & 0.191149 & 0.117557 & 2.22454545 \\
\hline
\end{tabular}


INTENSIF, Vol.3 No.1 February 2019

ISSN: 2580-409X (Print) / 2549-6824 (Online)

Website: http://ojs.unpkediri.ac.id/index.php/intensif

B. Perangkingan Rumah

Hasil yang didapatkan dari perhitungan AHP adalah total nilai bobot akhir dari rumah.

Total nilai bobot rumah akan diurutkan dari nilai yang tertinggi hingga nilai yang terendah.

Nilai total bobot tertinggi berarti nilai yang paling baik berdasarkan perhitungan kriteria pemilihan rumah yang telah ditentukan.

Dari contoh perhitungan tabel 10, maka hasilnya adalah rangking-1 adalah rumah-1 dengan total 2.62110174 dan merupakan hasil pilihan rumah yang paling baik dan sesuai dengan kriteria yang telah ditentukan.

C. Implementasi

1. Gambar 3 merupakan Form Data Kriteria, user bisa membuat data kriteria yang sesuai dengan kebutuhan.

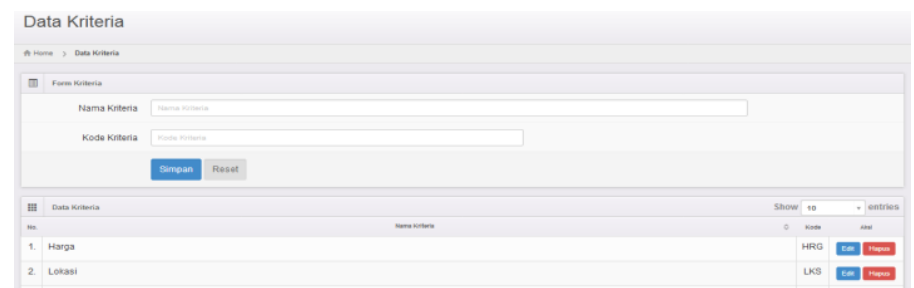

GAMBAR 3. IMPLEMENTASI FORM DATA KRITERIA

2. Gambar 4 merupakan Form nilai kepentingan, menginputkan nilai kepentingan antar kriteria satu dengan yang lain atau biasa disebut matriks berpasangan.

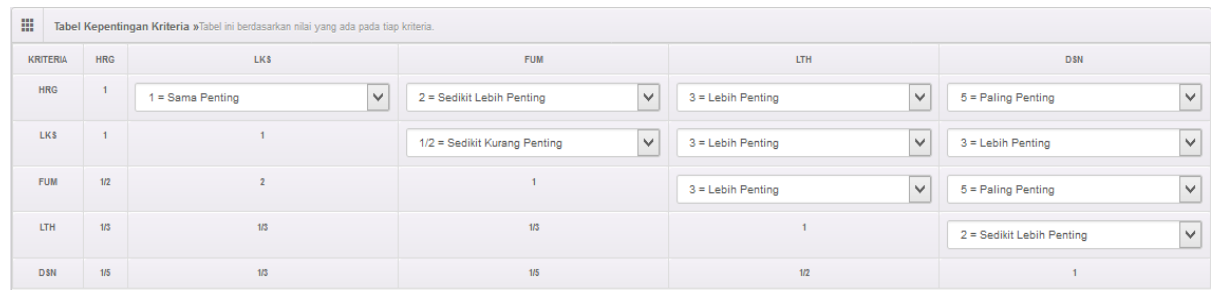

Gambar 4. IMPLEMENTASI FORM NILAI KEPENTINGAN KRITERIA

3. Gambar 5 merupakan Form data referensi, mengatur alternatif kriteria serta nilainya. Pada penilian ini ada tiga jenis alternatife kriteria, misalkan untuk harga yaitu mahal, sedang dan murah, lalu diberikan nilai untuk dijadikan acuaan untuk perhitungan ahp.

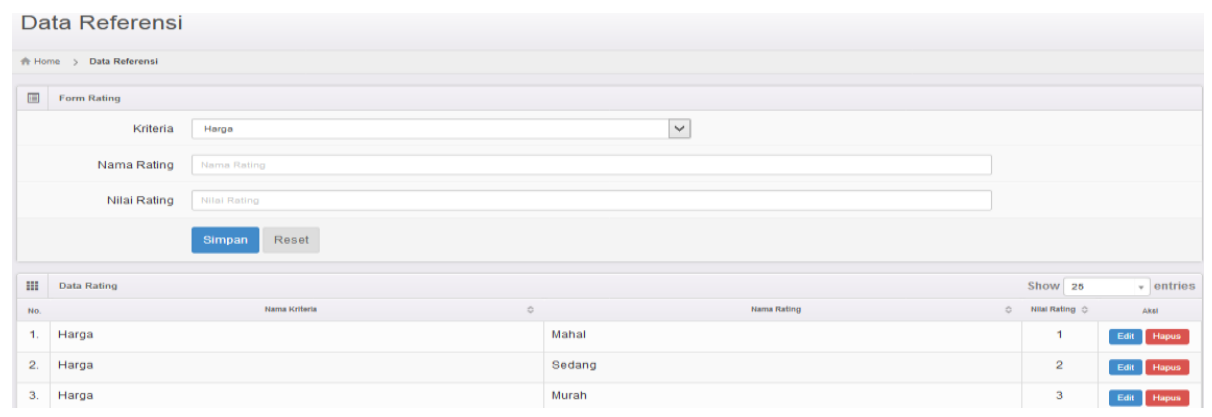

Gambar 5. IMPLEMENTASI FORM DATA REFERENSI 
4. Gambar 6 merupakan Form Data Rumah, user bisa menginputkan data rumah yang berisi nama rumah dan gambar rumah.

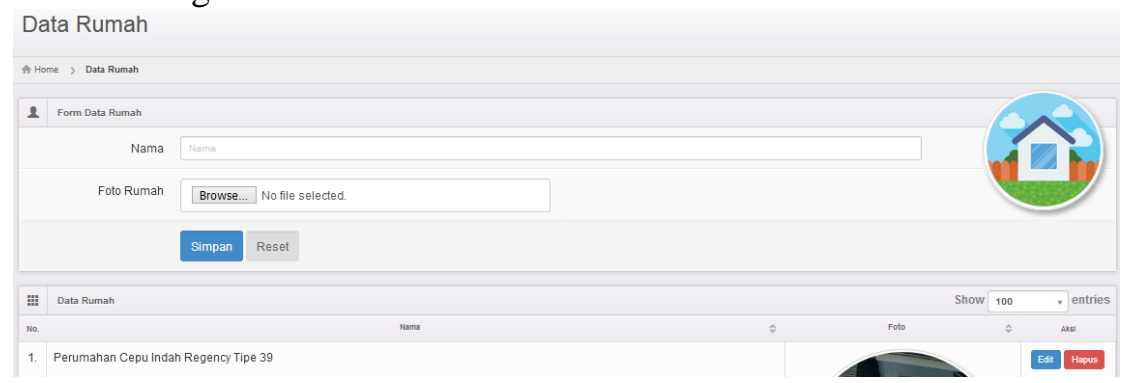

Gambar 6. IMPLEMENTASI FORM DATA RUMAH

5. Gambar 7 merupakan Form Data nilai rumah, menginputkan nilai rumah sesuai dengan kriteria rumah yang dinilai.

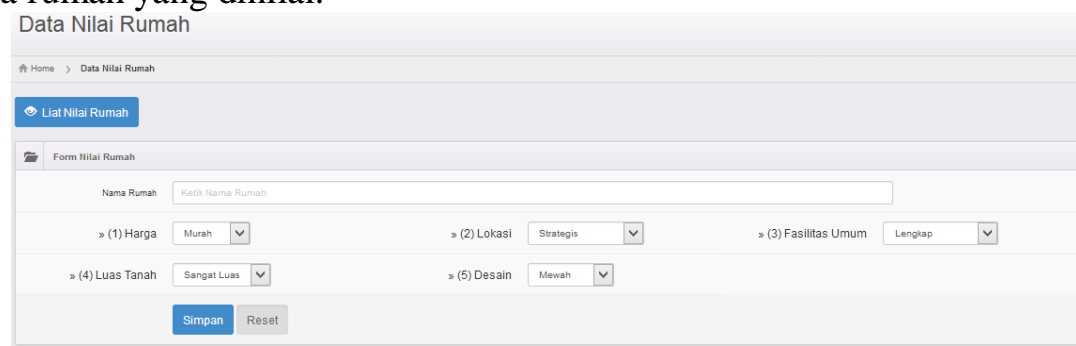

\section{Gambar 7. IMPLEMENTASI FORM DATA NILAI RUMAH}

6. Gambar 8 merupakan Form Data nilai rumah keseluruhan, menampilkan nilai rumah secara keseluruhan menurut kriteria rumah

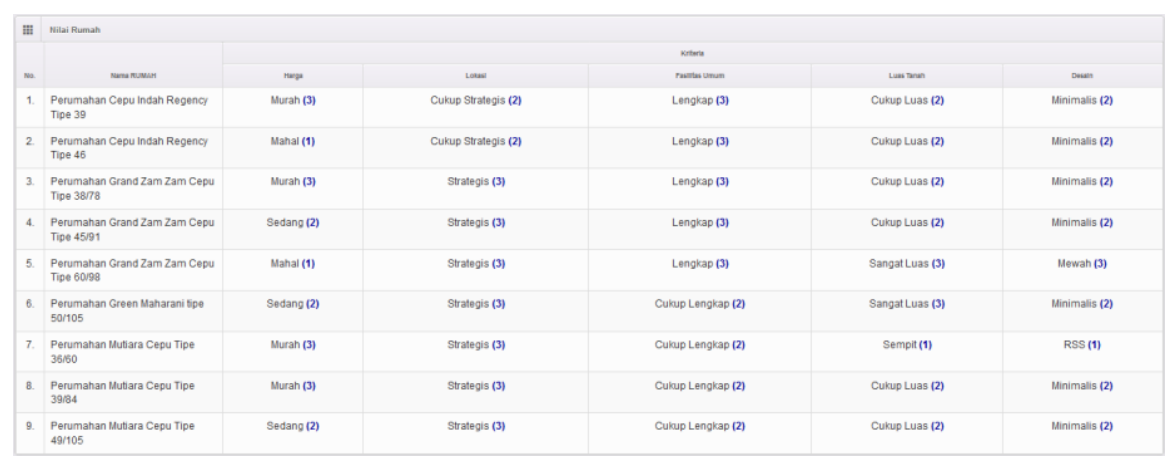

Gambar 8. IMPLEMENTASI FORM DATA NILAI RUMAH SECARA KESELURUHAN

7. Gambar 9 merupakan Form perhitungan nilai rumah, menampilkan hasil perhitungan atau hasil nilai rumah dari total nilai sekuruh nilai kriteria rumah.

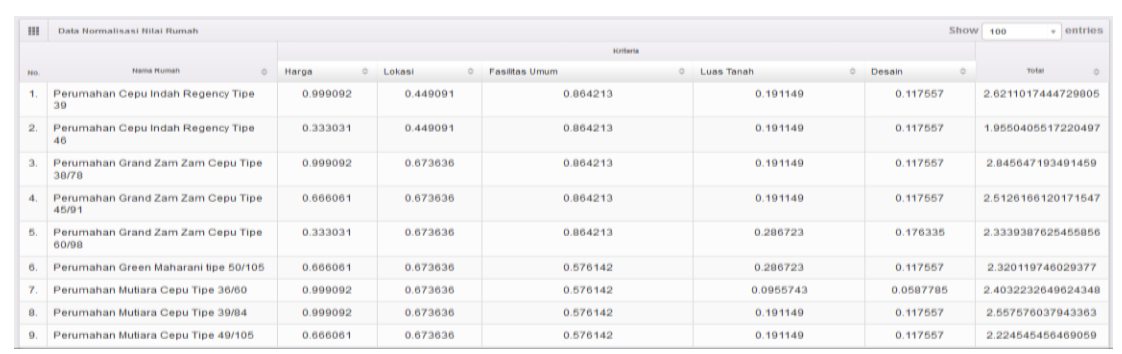

Gambar 9. IMPLEMENTASI FORM PERHITUNGAN NILAI RUMAH 
INTENSIF, Vol.3 No.1 February 2019

ISSN: 2580-409X (Print) / 2549-6824 (Online)

Website: http://ojs.unpkediri.ac.id/index.php/intensif

8. Gambar 10 merupakan Form hasil akhir akhir penilaian, menampilkan rumah dengan tertinggi hingga rumah dengan nilai terendah / perangkingan.

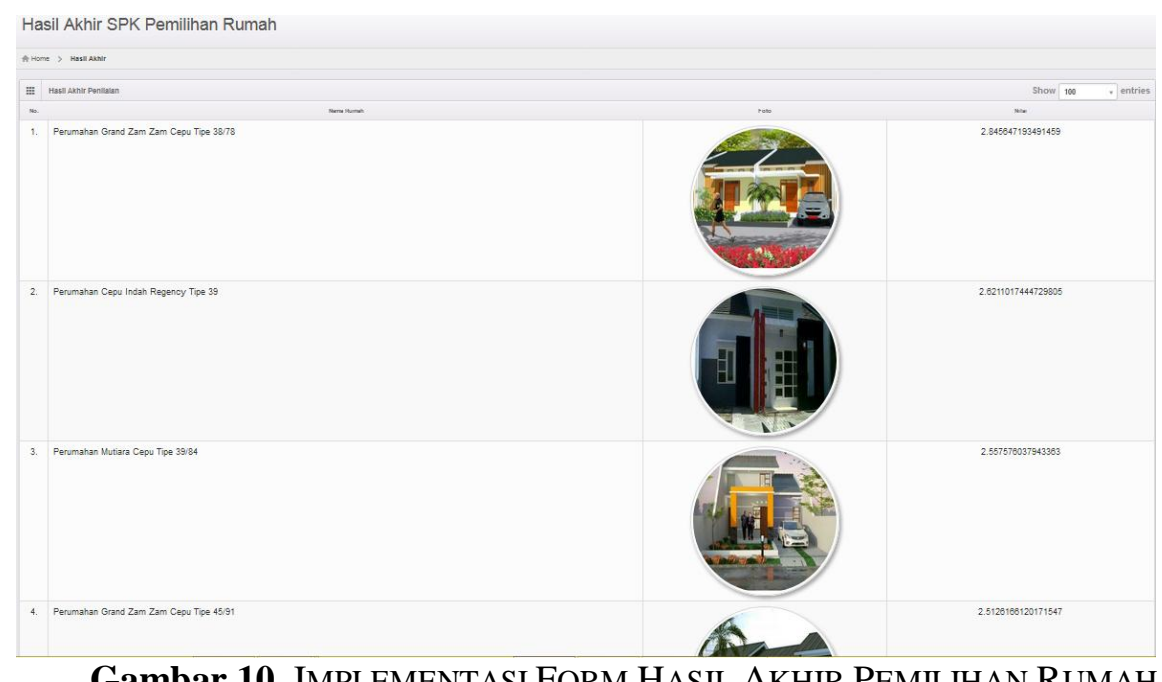

\section{KESIMPULAN DAN SARAN}

Berdasarkan hasil pembahasan penelitian ini, maka dapat diambil kesimpulan bahwa Pembangunan aplikasi sistem pendukung keputusan pemilihan rumah dengan menggunakan metode AHP dapat dijadikan sebagai analisis dalam menentukan pilihan rumah. Total 9 sample rumah di kawasan Cepu, yang mendapatkan nilai tertinggi adalah Perumahan Grand Zam Zam Cepu Tipe 38/78 dengan total nilai 2,845647193. Pengujian dengan menggunakan BlackBox yang berfokus pada uji fungsionality Aplikasi Sistem Pendukung Keputusan Pemilihan Rumah dengan Menggunakan Metode AHP didapatkan hasil 100\% dari 20 orang yang menguji.

Saran untuk penelitian tentang sistem pendukung keputusan pemilihan rumah di perumahan kawasan Cepu menggunakan metode AHP agar sampel rumah yang dipakai lebih banyak lagi, sehingga referensi dari pemilihan rumah semakin bervariatif. 
INTENSIF, Vol.3 No.1 February 2019

ISSN: 2580-409X (Print) / 2549-6824 (Online)

Website: http://ojs.unpkediri.ac.id/index.php/intensif

\section{DAFTAR PUSTAKA}

[1] E. Widiastuti and S. Handayani, "Analisis Faktor-Faktor yang Mempengaruhi Keputusan Pembelian Rumah Bersubsidi dengan Menggunakan Analisis Regresi," in Prosiding Seminar Nasional Statistika Universitas Diponegoro. Fakultas Ekonomi, Universitas Diponegoro. Semarang, 2013.

[2] A. Suhartanto and S. Sucipto, "Penggunaan Expert System Dalampemilihan Varietas Padi Berdasarkan Kondisi Lahan Studi Kasus: Gapoktan Ds. Kleco, Kec. Wungu - Kab. Madiun," Semin. Nas. Teknol. Inf. dan Multimed. 2016, p. 3.4-19-3.4-24, 2016.

[3] S. Sucipto, "Analisa Hasil Rekomendasi Pembimbing Menggunakan Multi-Attribute Dengan Metode Weighted Product," Fountain Informatics J., vol. 2, no. 1, p. 27, May 2017.

[4] S. Sucipto, "Sales Transaction Result Analysis for Increase Prediction of Income," Fountain Informatics J., vol. 3, no. 2, pp. 31-35, 2018.

[5] A. P. Widyassari, "Aplikasi Sistem Pendukung Keputusan Penilaian Kinerja Karyawan untuk Kenaikan Gaji pada PT AAA," INTENSIF, vol. 1, no. 2, pp. 92-101, 2017.

[6] W. A. W. Supriyono, "Sudaryo, Sistem Pemilihan Pejabat Struktural dengan Metode AHP," 2007.

[7] T. L. Saaty, "Decision making with the analytic hierarchy process," Int. J. Serv. Sci., vol. 1, no. 1, pp. 83-98, 2008.

[8] S. R. I. MARDIYATI, J. JULIANA, and D. DRIYANI, "SISTEM PENUNJANG KEPUTUSAN PEMILIHAN PERUMAHAN DENGAN MENGGUNAKAN METODE AHP,” Fakt. Exacta, vol. 9, no. 1, pp. 63-71, 2016.

[9] A. Suwandi, "PENGAMBILAN KEPUTUSAN PEMILIHAN PERUMAHAN MENENGAH DAN SEDERHANA DI KABUPATEN SUMENEP DENGAN ANALYTICAL HIERARCHY PROCESS," EXTRAPOLASI J. Tek. Sipil, vol. 8, no. 2, 2015.

[10] Sugiyono, Metode penelitian pendidikan:(pendekatan kuantitatif, kualitatif dan $R \& D$ ). Alfabeta, 2008.

[11] T. L. Saaty, "Pengambilan keputusan bagi para pemimpin, proses hirarki analitik untuk pengambilan keputusan dalam situasi yang kompleks," Pustaka binama Press., vol. 100, 1993.

[12] A. Y. Ranius, "Sistem Penunjang Keputusan Penetapan Dosen Pembimbing dan Penguji Skipsi Dengan Menggunakan Metode AHP," in Digital Information \& Systems Conference (DISC) 2014, 2014, vol. 1, pp. 80-85. 